\title{
Desafios para o concreto sustentável
}

\section{Danillo de Almeida e Silva* e Carlos Eduardo Luna de Melo}

Universidade de Brasília. Faculdade de Arquitetura e Urbanismo. Campus Universitário Darcy Ribeiro. Asa Norte. Brasília-DF, Brasil (CEP 70842-970). *E-mail: arq.danillo@gmail.com.

Resumo. 0 presente artigo busca referenciar a problemática do uso do agregado reciclado para concreto e os mecanismos relacionados à sua produção e qualidade, fatores que são preponderantes no desempenho do concreto reciclado. Os critérios elaborados para esse estudo têm como base os fatores que influenciam nas propriedades físicas, mecânicas e ambientais do agregado reciclado, tais como conscientização da mão de obra, processo de coleta, processo de beneficiamento e produção do concreto reciclado. 0 uso dos resíduos de construção e demolição como agregado para produção de concretos reciclados, blocos estruturais, blocos de vedação e outros componentes construtivos são uma realidade promissora, e estão sendo difundidos e implementados em vários países com potenciais ganhos ambientais. Bons estudos estão sendo realizados em vários países sobre o uso do agregado reciclado para concretos sustentáveis. Os mecanismos para mitigar a problemática do uso deste material tão abundante tem difundindo cada vez mais o potencial deste material sustentável. A pesquisa teve como alvo periódicos de pesquisas realizadas no Brasil e no exterior, normas brasileiras e portarias que normatizam o uso do resíduo de construção e demolição como agregado para concreto e materiais construtivos, tendo como enfoque a produção com sustentabilidade. 0 processo de beneficiamento do resíduo de construção e demolição tem forte influência nas propriedades mecânicas dos agregados, tais como granulometria, forma, textura e densidade, e podem ser controladas melhorando o desempenho do concreto reciclado e potencializando o seu ganho ambiental.

Palavras-chave: Resíduo; Demolição; Concreto; Sustentabilidade.

Abstract. The challenge for sustainable concrete. This article seeks to refer to the problem of the use of recycled aggregate for concrete and the mechanisms related to its production and quality, factors that are preponderant in the performance of recycled concrete. The criteria developed for this study are based on the factors that influence the physical, mechanical and environmental properties of the recycled aggregate, such as: awareness of labor, collection process, beneficiation process and production of recycled concrete. The use of construction and

ISSN 2359-1412/RBGAS-2020-0138/2020/7/17/32/1543

Rev. Bras. Gest. Amb. Sustent.

http://revista.ecogestaobrasil.net 
demolition wastes as an aggregate for the production of recycled concrete, structural blocks, sealing blocks and other construction components is a promising reality, and is being disseminated and implemented in several countries with potential environmental gains. Good studies are being carried out in several countries on the use of recycled aggregate for sustainable concrete. The mechanisms to mitigate the problem of using this abundant material have increasingly spread the potential of this sustainable material. The research was aimed at periodical research carried out in Brazil and abroad, Brazilian standards and ordinances that regulate the use of construction and demolition waste as aggregate for concrete and construction materials, with a focus on sustainable production. The process of processing the construction and demolition waste has a strong influence on the mechanical properties of the aggregates, such as granulometry, shape, texture and density, and they can be controlled by improving the performance of recycled concrete and enhancing its gain environmental.

Keywords: Waste; Demolition; Concrete; Sustainability.

Resumen. El desafío para el hormigón sostenible. Este artículo busca referirse al problema del uso de agregado reciclado para concreto y los mecanismos relacionados con su producción y calidad, factores que son preponderantes en el desempeño del concreto reciclado. Los criterios desarrollados para este estudio se basan en factores que influyen en las propiedades físicas, mecánicas y ambientales del agregado reciclado, tales como conocimiento de la mano de obra, proceso de recolección, proceso de beneficio y producción de concreto reciclado. El uso de residuos de construcción y demolición como un agregado para la producción de hormigón reciclado, bloques estructurales, bloques de sellado y otros componentes de la construcción es una realidad prometedora, y se está difundiendo e implementando en varios países con beneficios ambientales potenciales. Se están realizando buenos estudios en varios países sobre el uso de áridos reciclados para hormigón sostenible. Los mecanismos para mitigar el problema del uso de este material abundante han extendido cada vez más el potencial de este material sostenible. La investigación tuvo como objetivo la investigación periódica realizada en Brasil y en el extranjero, las normas y ordenanzas brasileñas que regulan el uso de residuos de construcción y demolición como agregado para hormigón y materiales de construcción, con un enfoque en la producción sostenible. El proceso de procesamiento de los residuos de construcción y demolición tiene una fuerte influencia en las propiedades mecánicas de los agregados, tales como granulometría, forma, textura $\mathrm{y}$ densidad, $\mathrm{y}$ pueden controlarse mejorando el rendimiento del hormigón reciclado y aumentando su ganancia ambiental.

Palabras clave: Residuos; Demolición; Concreto; Sostenibilidad. 


\section{Introdução}

A indústria da construção civil é a atividade humana com maior impacto sobre o meio ambiente. Estudos realizados pelos pesquisadores Ribeiro e Dias (2013), Brasileiro e Matos (2015), Cortese et al. (2019) estimam que 50\% dos recursos naturais extraídos estão relacionados à atividade de construção. Esta é, ainda, a responsável por aproximadamente $15 \%$ do produto interno bruto (PIB) brasileiro, pela geração de 62 empregos indiretos para cada 100 empregos diretos e pela redução do déficit habitacional e da infraestrutura, indispensáveis ao progresso (Karpinsk et al., 2009).

É natural que, tendo um papel tão representativo na economia mundial, a construção civil seja também um dos grandes problemas ambientais. Cerca de $80 \%$ da energia utilizada na produção de um edifício é consumida na produção e transporte de materiais. Além disso, gera poluição em quase todos os seus processos, desde extração de matérias-primas, à produção de produtos como cimento e concreto. Até mesmo na fase de uso dos edifícios os impactos ambientais são inúmeros. Dados mostram que o volume de recursos consumidos na fase de manutenção da edificação é praticamente igual ao consumido durante a construção do edifício (Cabral et al., 2009).

As atividades de construção demandam uma notável quantidade de materiais inertes, tais como areia e cascalho, que usualmente são fornecidos por meio da extração de sedimentos aluviais. A extração desses sedimentos modifica o perfil dos rios e o seu equilíbrio, além de introduzir problemas ambientais como a modificação em sua estrutura hidrológica e hidrogeológica. A extração de material inerte de formações rochosas em áreas acidentadas e montanhosas também é uma danosa atividade ao meio ambiente, uma vez que altera a paisagem e provoca problemas de instabilidade ambiental (Lintz et al., 2012).

A Indústria da Construção Civil constitui-se numa grande fonte geradora de resíduos. Cerca de $30 \%$ de todo material empregado por ela é descartado como Resíduos de Construção e Demolição (Brasileiro e Matos, 2015). Com relação à geração de resíduo, no Brasil, algumas estimativas indicam valores da ordem de $230 \mathrm{~kg}^{-1} \cdot \mathrm{hab}^{1}$.ano a $760 \mathrm{~kg}^{-1}$.hab ${ }^{-1}$.ano (IPEA, 2012) e outros apontam para valores próximos a 68,5 Mt/ano (Silva et al., 2015). Conforme Brasileiro e Matos (2015), o RCD constitui uma importante parcela dos Resíduos Sólidos Urbanos (RSU), correspondendo em torno de 50\% dos resíduos gerados nos grandes centros urbanos.

A falta de gerenciamento desses resíduos afeta as cidades nos aspectos sociais, econômicos e ambientais. Desta forma, ações no sentido de enfrentar este problema tiveram início no final da década de 1980 em alguns países da Europa, enquanto que no Brasil, somente no início do século XXI. 0 Brasil, até 2002, não tinha políticas públicas para os resíduos gerados pelo setor da construção civil. Em 5 de Julho de 2002, entrou em vigor a Resolução CONAMA no 307/2002 (Brasil, 2002), a qual estabelece diretrizes, critérios e procedimentos para a gestão dos resíduos da construção civil, visando a proporcionar benefícios de ordem social, econômica e ambiental. Em 16 de agosto de 2004, entrou em vigor a Resolução CONAMA no 348/2004 (Brasil, 2004), que altera o art. 3oㅡㄹ item IV, da Resolução CONAMA no 307/2002 (Brasileiro e Matos, 2015).

Segundo Brasileiro e Matos (2015), o crescente consumo de agregados naturais juntamente com a crescente produção de RCD e as diretrizes da Resolução CONAMA no 307/2002 (Brasil, 2002) e da Lei no 12.305/2012 (Brasil, 2012), que instituiu a Política Nacional de Resíduos Sólidos PNRS, têm levado à consolidação de técnicas de reciclagem. 0 uso de agregados reciclados em misturas asfálticas tem sido um tema interessante para a proteção do ambiente e desenvolvimento sustentável.

Rev. Bras. Gest. Amb. Sustent., 2020, vol. 7, n. 17, p. 1533-1541. 
De acordo com Buttler (2007), menos de 10\% do resíduo gerado na construção e demolição tem um tratamento adequado como: coleta, separação, processamento e destinação para confecção de novos produtos. Estes podem ser: blocos estruturais, blocos para vedação, blocos para piso, telhas, agregado graúdo e agregado miúdo artificial para concreto e argamassa.

Estudos realizados por Santana et al. (2011) mostram que o concreto reciclado já vem demonstrando uma boa atuação numa série de usos em obras urbanas, com a obtenção de custos bastante benéficos. É possível programar sua utilização em concretos para bases de pavimentos, estruturas residenciais com Fck $<20$ MPa e produção de artefatos pré-moldados em concreto (tubos, lajes, blocos).

Tendo em mente a grandiosidade da cadeia produtiva da Indústria da Construção Civil, fica claro que não é possível alcançar o desenvolvimento sustentável sem que a indústria da construção também se torne sustentável (Brasileiro e Matos, 2015).

\section{Resíduos de construção e demolição}

As origens dos Resíduos da Construção e Demolição (RCD) advêm de várias fontes da construção civil, entre as quais temos estruturas de concreto, argamassas, elementos de vedação e revestimentos, que podem ser compreendidos em determinadas fases de uma obra. A reciclagem de entulho de obras de construções tem o objetivo de preservar o meio ambiente, suprindo a demanda de novos materiais e dando destinação sustentável aos resíduos, que seriam descartados em aterros ou despejados de forma irregular às margens de rios e córregos.

Estudos examinaram o uso de resíduos de concretos e resíduos cerâmicos advindos da construção como fontes de matéria prima para uso como agregados graúdos para concreto (Gomes e Brito, 2007; Amorim e Brito, 2012; Silva et al., 2014). Outras pesquisas abordaram o uso destes resíduos como agregado graúdo e agregado miúdo para concreto (Alves et al., 2014; Stroher et al., 2017). Pesquisadores como Gomes e Brito (2007), Amorim e Brito (2012), Bravo et al. (2015), Martins et al. (2016) possuem uma ampla pesquisa no uso do agregado de concreto reciclado para produção de concretos sustentáveis.

Neste contexto, pesquisas têm sido realizadas sobre a alternativa de aproveitamento de resíduo de cerâmica vermelha, proveniente de tijolos e blocos cerâmicos, em compósito de cimento Portland. Este tema tem sido o objeto de alguns trabalhos, como os de Senthamarai e Devadas Manoharan (2005) em que foram comparadas propriedades, como resistência à compressão, tração por compressão diametral, resistência à flexão, módulo de elasticidade, absorção de água, retração, porosidade aparente e variações dimensionais por oscilação de umidade. As comparações sempre são feitas entre concretos com agregados oriundos de resíduos reciclados e concretos moldados com agregados comumente utilizados, provenientes da britagem de rocha.

\section{Concreto e argamassas}

Os entulhos de concretos e argamassa são classificados como classe A, pela Resolução CONAMA no 307/2002 (Brasil, 2002), e são passíveis de reciclagem, podendo ser classificados como agregados graúdos e miúdos "areia e brita". E dentre dos materiais do RCD, os concretos são os mais promissores para a reciclagem e produção de agregados para a Indústria da Construção Civil.

\section{Cerâmica vermelha}

Segundo a Resolução CONAMA no 307/2002 (Brasil, 2002) material cerâmico é classificado como classe A de entulho (resíduos recicláveis), podendo ser aproveitados 
como agregados miúdos e graúdos "areia e brita" para a Indústria de Construção Civil. Compreende aqueles materiais com coloração avermelhada empregados na construção civil (tijolos, blocos, telhas, elementos vazados, lajes, tubos cerâmicos e argilas expandidas) e também utensílios de uso doméstico e de adorno. As lajotas muitas vezes são enquadradas neste grupo, porém o mais correto é que sejam colocadas em materiais de revestimento (ABCERAM, 2019).

\section{Revestimentos e placas cerâmicas}

São os materiais na forma de placas usados na construção civil para revestimento de paredes, pisos, bancadas e piscinas de ambientes internos e externos. Recebem designações tais como: azulejo, pastilha, porcelanato, lajota, piso (ABCERAM, 2019).

\section{Uso do RCD-R como agregado para construção civil}

A necessidade de desenvolver concretos com agregados não convencionais é urgente por razões ambientais e econômicas. Pesquisas realizadas mostram que os resíduos industriais e outros subprodutos como escória, filer e pozolana foram adicionados na fabricação de cimentos "aglomerantes hidráulicos" utilizados para fabricação de concretos com o objetivo de melhorar as propriedades do concreto e reduzir seu custo (Bastos et al., 2016). Atualmente, o intuito de incorporar o RCD-R como agregado no concreto estrutural e não estrutural, não é uma alternativa e sim um objetivo para a sustentabilidade da construção civil (Brasil, 2002; Katz, 2004; Bastos et al., 2016).

Conforme Mesquita et al. (2015) a reciclagem na construção civil pode gerar muitos benefícios, com reflexo direto na redução do consumo de recursos naturais não renováveis. Alternativas sustentáveis têm sido avaliadas em relação à utilização dos resíduos de construção e demolição reciclados como agregados em obras de pavimentação, na produção de argamassas, blocos e artefatos de concreto, em sistemas de drenagem e muros de peso em obras de contenção, entre outros.

A forma mais difundida de tratamento dos RCDs consiste na segregação da fração mineral, que é triturada até a granulometria desejada, e, utilizada na própria Indústria da Construção Civil (Mesquita et al., 2015). Com este objetivo, novos estudos de Campos et al. (2018), El-Dieb e Kanaan (2018), Saeedi et al. (2018), Thomas et al. (2018), Wong et al. (2018) e Shaban et al., (2019a) têm sido implementados na utilização do RCD para concretos sustentáveis. Além de reduzir a destinação irregular desses resíduos, evitando a poluição do meio natural, também poderão trazer razoável economia para as obras de engenharia.

As plantas de reciclagem para o processamento desses resíduos são constituídas essencialmente de um alimentador vibratório, britador primário/secundário e peneirador vibratório. Tais instalações são classificadas como plantas de reciclagem de primeira geração. No país, existem apenas 18 instalações de reciclagem públicas e privadas com escala de produção pequena (cerca de 100 toneladas/dia de resíduos processados). Algumas estimativas indicam um montante de 68,5 toneladas a 106 toneladas de resíduos de construção e demolição por ano, sendo que, com as instalações em operação no país, apenas 1\% desse montante poderá ser reciclado (Buttler et al., 2006). Com esses dados pode-se aferir que o Brasil apresenta um déficit de pelo menos 2.600 usinas de reciclagem que seriam necessárias para processar o volume de resíduos gerados diariamente (Buttler et al., 2006).

Devido ao déficit de instalações de reciclagem e ao elevado custo de transporte, algumas empresas privadas e fábricas de pré-moldados estão investindo na aquisição de equipamentos de reciclagem, com o intuito de reciclar os resíduos de concreto na própria fonte de geração (Buttler et al., 2006; Brasileiro e Matos, 2015). Desta forma, a triagem dos resíduos pode ser melhor aplicada, eliminando os contaminantes tão indesejáveis. E 
influenciando o principal agente causador do RCD, a mão de obra da indústria da construção civil, pode-se iniciar uma corrente de sustentabilidade na construção.

\section{Meio ambiente sustentável}

Tereza et al. (2020) relata que o estudo da sustentabilidade justifica-se diante da realidade de que as futuras gerações do planeta sofrerão os impactos da contínua exploração de recursos naturais.

0 fenômeno de urbanização das cidades e o consequente adensamento das mesmas, levaram a uma mudança no sentido da palavra progresso, quando se passou a perceber que o mesmo só acontece em sua plenitude quando também são consideradas as questões ambientais. Em 1987, com o surgimento do conceito de desenvolvimento sustentável no Relatório de Brundtland, como um modelo de desenvolvimento que visa a não apenas o momento atual, mas também garante condições às próximas gerações de se desenvolverem, fez com que grande parte da sociedade se tornasse cada vez mais exigente em relação ao meio ambiente (Carneiro, 2005).

No Brasil, a partir de 2002, diretrizes foram estabelecidas pelo Conselho Nacional do Meio Ambiente (CONAMA), através da Resolução CONAMA no 312/2002 (Brasil, 2002), com critérios e procedimentos para o descarte de resíduos de construção e demolição. Desde então, a fiscalização quanto a essa problemática tornou-se efetiva por parte do governo (Bastos et al., 2016). A Resolução considera que: “[...] é dos geradores a responsabilidade sobre os resíduos produzidos pelas atividades de construção, reforma, reparos e demolições, bem como daqueles oriundos da remoção de vegetação e escavação de solos" (Brasil, 2002).

Estudo realizado por Tereza et al. (2020) evidencia que a seleção de materiais e componentes visando à redução do consumo de energia e outros recursos, das emissões de poluentes como o $\mathrm{CO}_{2}$ e da toxidade devem ser uma das prioridades para a sustentabilidade da construção. Também não devem ser deixadas de lado questões relacionadas aos custos e aos socioculturais destes impactos materiais e componentes.

\section{Problemática do uso do resíduo de construção e demolição reciclado como agregado para concreto}

Uma política cultural está sendo introduzida nos canteiros de obras, com a finalidade de conscientização dos profissionais, com o objetivo de minimizar o descarte inadequado destes materiais (Bastos et al., 2016). Outro fator preponderante está ligado a qualidade do agregado produzido como: forma do agregado, granulometria, quantidade de finos, e dentre este, a quantidade de argamassa aderida "argamassa velha" como fator influente na porosidade, e durabilidade do concreto.

A maior problemática relacionada ao uso do RCD-R na construção civil está ligada à sua qualidade e o processo de britagem é o fator primordial deste resultado. Contudo, a argamassa aderida ao agregado reciclado torna-se o elo fraco no concreto reciclado (Katkhuda e Shatarat, 2017; Guo et al., 2018; Kim et al., 2018; Shaban et al., 2019a, b).

Estudos realizados por Hansen (1986) relatam que o "elo fraco" do concreto utilizando agregado reciclado é a argamassa aderida (argamassa velha), que tem forte efeito sobre a resistência do concreto com agregado reciclado.

Estudos realizados em concretos produzidos com agregados reciclados RCD-R apresentam uma perda de trabalhabilidade e aumento do consumo de cimento devido à alta absorção da água desse material (Malešev et al., 2010). Essa característica ocorre em função do aumento da relação água/cimento, redução da massa específica, permeabilidade e composição dos agregados reciclados (Frotté et al., 2017; Tenório et al., 2012).

Pesquisas realizadas por Hansen (1986) fazem referência à problemática do uso de agregados reciclados para produção de novos concretos, sendo o "elo fraco" entre agregado reciclado/pasta aderida e argamassa nova. Estudos recorrentes fazem referência 
ao "elo fraco" e a argamassa aderida do agregado reciclado, segundo Hansen (1986), bem como pesquisas realizadas por Gomes e Brito (2009), Poon et al. (2004), Tam et al. (2005).

Grandes pesquisas vêm sendo conduzidas a respeito da tecnologia do concreto reciclado. Estudos realizados por Poon et al. (2004) investigaram o efeito da microestrutura da Zona de Transição (ZT) e a influência da pasta de cimento/agregado na resistência à compressão do concreto com agregado reciclado (Poon et al., 2004). Uma análise da micro propriedade do concreto, em um microscópio eletrônico de varredura, revelou que a zona interfacial da matriz agregado/cimento do concreto reciclado (CR) consistia principalmente de hidratos soltos e porosos, enquanto a zona interfacial da matriz agregado/cimento do concreto convencional com agregado natural, consistia principalmente de hidratos densos. Tam et al. (2005) constataram que a microestrutura do concreto com agregado reciclado é mais complicada que a do concreto convencional. 0 CR possui duas ZT's: uma entre o agregado reciclado (AR) e a nova matriz de argamassa, e uma segunda entre a AR e a argamassa velha (velha ZT), (Le et al., 2017; Leite e Monteiro, 2016). A argamassa velha do AR forma o elo fraco no concreto reciclado, que é composto por uma vasta rede de poros e rachaduras. A Figura 1 apresenta o detalhe da argamassa aderida ao agregado reciclado.

Os experimentos realizados por Vieira et al. (2016) constatam que a argamassa velha adere inerentemente às superfícies do agregado original e torna-se parte do agregado reciclado. Devido à natureza da argamassa, que é menos densa e mais porosa que o agregado, essa argamassa antiga cria um sistema mais leve no agregado reciclado (Verian et al., 2018). A presença dessas argamassas velhas acabam aumentando a capacidade de absorção e diminuindo a massa específica do agregado reciclado, em comparação com a maioria dos naturais (Kisku et al., 2017).

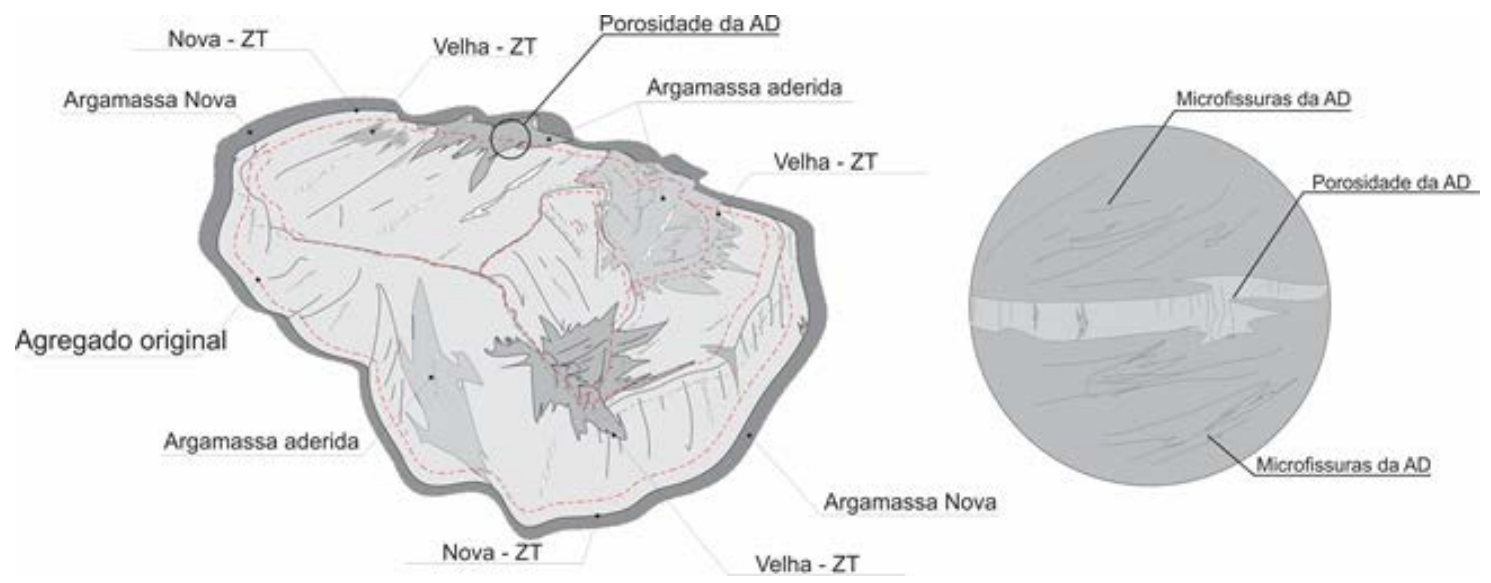

Figura 1. Detalhe agregado reciclado com argamassa velha/nova - microfissuras.

Uma abordagem mais confiável para determinar o desempenho desejado do concreto com agregado reciclado, só pode ser feita esclarecendo as possíveis mudanças microestruturais trazidas pelo processo de reciclagem em cada componente do agregado reciclado de concreto (Nagataki et al., 2004).

Um estudo de Vieira et al. (2016) examinou a seção transversal de um agregado reciclado imerso em líquido epóxi para determinar a porcentagem de argamassa aderida às suas superfícies, usando um microscópio óptico. 0 resultado indicou que a porcentagem de argamassa aderida a superfície do agregado reciclado é de até $28,9 \%$. Outros estudos 
abordam a quantidade de argamassa aderida ao agregado reciclado. Etxeberria et al. (2007) relataram que nos agregados de RCA utilizados em seu estudo, os contaminantes da argamassa antiga são cerca de $20 \%$ e $40 \%$ para duas frações diferentes de agregado reciclado. Afroughsbet et al. (2017) quantificaram a argamassa acoplada em até $24 \%$ e $38 \%$ em dois tipos de agregado reciclado utilizados em seu estudo.

\section{beneficiamento \\ o resíduo de construção e demolição reciclado e seu processo de}

As escolhas do processo de fragmentação (britagem) são cruciais para estabelecer as condições mais favoráveis e viáveis economicamente para a reciclagem de RCD e para a utilização do RCD-R na produção de concretos estruturais e não estruturais (Gomes et al., 2015).

0 processo de beneficiamento pode também ser uma alternativa para se obterem agregados reciclados com características apropriadas. Gomes et al. (2015) demonstraram que a fragmentação de agregados por diferentes processos reduz a porosidade do material e, muitas vezes, favorece a obtenção de características similares às do material natural (Cordeiro et al., 2017). A massa específica dos agregados graúdos provenientes de RCD-R reciclado podem variar entre $2,675 \mathrm{~g} / \mathrm{cm}^{3}$ e $2,740 \mathrm{~g} / \mathrm{cm}^{3}$ conforme estudos realizados por Silva e Arnosti (2005) e esta unidade pode ser influenciada pelo processo de britagem (Silva e Geyer, 2018a).

Em estudos de Gomes et al. (2015), Silva e Melo (2020) demonstraram que os agregados de concreto reciclados possuem pasta de cimento porosa aderida à superfície dos grãos reciclados, demonstrado esquematicamente na Figura 2. Os agregados utilizados para o experimento sobre agregado reciclado não obtiveram a forma original, não sendo possível visualizar a forma dos agregados naturais utilizados no concreto original após o processo de britagem, devido à alta quantidade de argamassa aderida (argamassa velha).

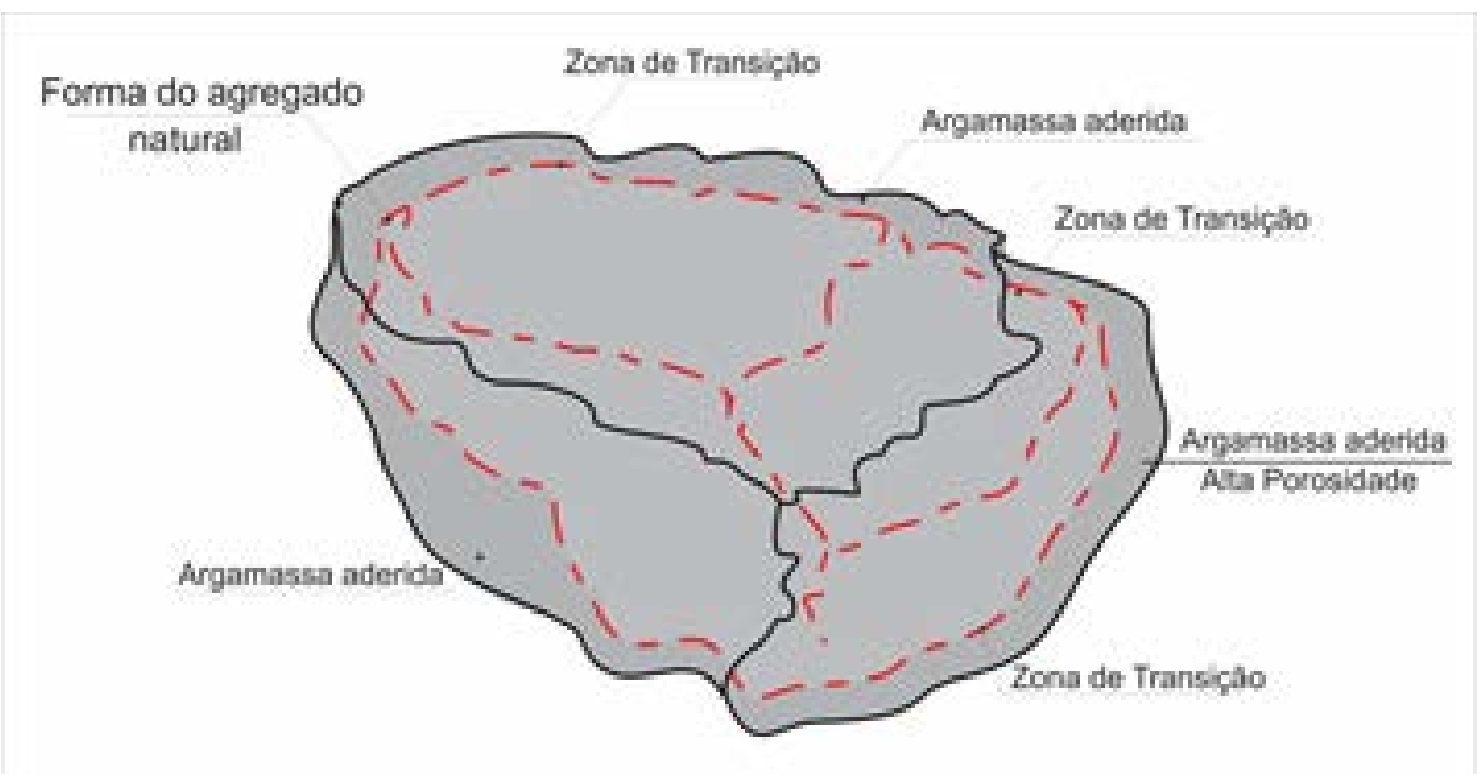

Figura 2. Detalhe: agregado reciclado/argamassa aderida. Fonte: Silva e Melo (2020).

Podemos deduzir, com base nos estudos de Silva e Geyer (2018b), sobre a influência da forma do agregado graúdo britado natural. 0 referido estudo apresenta informações pertinentes sobre o processo de britagem e sua relação com a forma das 
partículas. Quanto menor a massa unitária do agregado, maior o percentual de partículas irregulares (partículas indesejadas para a produção de concreto) (Silva et al., 2020a).

Britadores de eixo vertical apresentam resultados mais satisfatórios em relação à forma adequada das partículas tanto para agregado natural e reciclado, como para produção de concretos, conforme experimento apresentado por (Silva, 2012). Com relação às misturas dos materiais em britadores com eixo vertical, Cordeiro et al. (2017) apresentou resultados semelhantes. Seus estudos mostram que ocorreu desagregação de partículas nas misturas realizadas em misturador de eixo vertical, para análise do comportamento entre o agregado natural e reciclado. Para a betoneira de eixo inclinado, a granulometria permaneceu praticamente inalterada, tanto para a ordem de mistura tradicional, quanto para a ordem de mistura modificada.

Podemos inferir, com base nos estudos de Silva (2012), que essa desagregação, relatada por Cordeiro et al. (2017), é proveniente de argamassa aderida (argamassa velha) que se desprende do agregado reciclado. Como resultado da energia aplicada na betoneira de eixo vertical e o atrito com outros agregados, é produzida uma maior quantidade de agregados finos.

Segundo Nagataki et al. (2004) e Silva et al. (2020b), a tecnologia de reciclagem influencia significativamente as propriedades do agregado. Nos estudos de Nagataki et al. (2004) foi utilizada uma combinação de britador de mandíbula e britador de impacto para processar o material triturado duas vezes, com um equipamento mecânico de moagem, a fim de minimizar a argamassa aderida (AD).

Em uma análise microscópica de varredura, em concretos produzidos com várias fases de britagem, verificou-se que reduziu consideravelmente a densidade das rachaduras no agregado reciclado, eliminando as partículas com microdefeitos e vazios irregulares, processando até novas fissuras insignificantes reintroduzidas. Apenas uma quantidade muito pequena de rachaduras pôde ser detectada na argamassa aderida ou na zona de transição interfacial. Consequentemente, os agregados de concreto reciclado, obtidos de vários estágios de processo de reciclagem, não apresentaram perda de integridade. Além disso, a extensão do processo de reciclagem até aumentou eficientemente o desempenho físico do agregado de concreto, reduzindo a argamassa aderente (Nagataki et al., 2004).

A fragmentação por diferentes estágios dos britadores remove parcialmente a antiga pasta de cimento aderida dos agregados reciclados e, assim, reduz a porosidade do concreto produzido com agregado reciclado (Tam et al., 2005; Ulsen et al., 2013).

Estudos realizados por Nagataki et al. (2004) mostraram que o uso de três estágios de britagem levou a uma redução da absorção de água do concreto com agregado graúdo britado em torno de $35 \%$ a $50 \%$, comparando com concretos produzidos com agregados britados em primeiro e segundo estágios de britagem.

\section{0 resíduo de construção e demolição e o avanço tecnológico no concreto}

Um abrangente trabalho experimental foi realizado por Hansen (1986); Xiao et al. (2012) no uso do agregado reciclado. Nesse trabalho descobriu-se que, em geral, o procedimento de dosagem de concretos com agregados reciclados não difere muito daquele para o concreto convencional. No entanto, é necessária adição de mais água para atingir uma trabalhabilidade adequada, devido à alta absorção de água do agregado reciclado. Tam et al. (2005) propuseram uma abordagem de mistura de dois estágios para melhorar a resistência à compressão do concreto com agregados reciclados e diminuir a variabilidade de resistência. Outros pesquisadores em outros países, como Cordeiro et al. (2017) e Etxeberria et al. (2007), também descobriram que os agregados reciclados que eram usados em condições úmidas, mas não saturados, podiam controlar as propriedades, a trabalhabilidade do concreto e a razão efetiva entre a relação água/cimento. 
O fator preponderante da utilização de agregados reciclados em concretos é a elevada absorção de água e o enfraquecimento da zona de transição agregado/pasta de cimento e a baixa resistência do agregado cerâmico. Segundo a metodologia apontada por Gomos e Brito (2009), Tam et al. (2005), a hidratação da pasta divide-se em duas etapas, sendo que a primeira tem o objetivo de envolver o agregado, possibilitando a sucção da pasta hidratada aos poros e aberturas do agregado reciclado. Na segunda etapa ocorre a cristalização, diminuindo a porosidade do agregado e do concreto como um todo. A segunda adição de água serve para hidratar o resto do cimento necessário para a composição do concreto, minimizando a porosidade da argamassa aderida ao agregado reciclado, elemento influenciador na porosidade do concreto com agregados reciclados. $\mathrm{Na}$ argamassa aderida em agregados reciclados (argamassa velha) formam restos de argamassa, que no processo de trituração não foi possível descolar/separar do agregado reciclado.

Cordeiro et al. (2017) apresenta um processo de mistura em três etapas. A primeira visa a umidificar o agregado graúdo reciclado. A segunda objetiva tratar a superfície do agregado com o cimento, tal qual a proposta de Tam et al. (2005), Tam e Tam (2008) e Gomes e Brito (2009), além de garantir que o agregado reciclado absorva a água da mistura. Já a terceira, na qual é adicionado o restante dos materiais necessários para a produção do concreto, visa a homogeneizar a mistura até atingir a consistência desejada.

Durante o beneficiamento do agregado reciclado, britagem, moagem, desmonte e processos de trituração, dentre vários outros, uns podem produzir agregados de melhor qualidade, segundo a forma, quantidade de argamassa aderida, quantidade de impurezas, entre outras. Com base nos estudos de Gomes et al. (2015), o processo de britagem em várias fases produz agregados com menor quantidade de argamassa aderida (argamassa velha). Essa argamassa se desprende devido a moagem do mecanismo de atrito, causando um aumento na quantidade de finos. Estes finos provenientes da argamassa de concreto e concreto estrutural, quando reciclados, contem finos em fase anidra (não hidratada). Estes resultados podem ser relacionados ao alto consumo de cimento nos concretos estruturais de aproximadamente $350 \mathrm{~kg} / \mathrm{m}^{3}$, e que devido à falta de controle tecnológico na produção do concreto e a relação água/cimento, não consegue hidratar 100\% do aglomerante hidráulico. Dessa forma, fica uma pequena parcela na mistura do concreto em fase anidra.

Estudos foram realizados por Nagataki et al. (2004) com análise microscópica sobre possíveis padrões de fissuração dentro das partículas de agregados graúdos reciclados. E com base em seus estudos, foram classificados em três categorias de fissuras: microaberturas no agregado graúdo, fissuras na argamassa aderida (AD) e rachaduras de interface da zona de transição (ITZ), entre o agregado e a AD. Foram analisadas microscopicamente os constituintes da partícula de agregado graúdo reciclado. A microscopia visual óptica das seções do agregado sob luz fluorescente forneceu informações úteis sobre os tipos de fissuras no agregado. As partículas tinham microfissuras com uma espessura de até $30 \mu \mathrm{m}$. Além desse microdefeito, algumas partículas tinham cavidades maiores independentes com $50 \mu \mathrm{m}$ de diâmetro.

Estudos relatados por Ulsen et al. (2013) confirmaram que mais estágios de britagem resultam em uma redução da absorção de água do agregado graúdo reciclado em aproximadamente $10 \%$ a $20 \%$, comparados com o uso de uma ou duas etapas de britagem. Já uma terceira etapa, utilizando um britador de eixo vertical, obteve uma redução de $40 \%$ a $60 \%$ na absorção de água do agregado reciclado.

Análises sobre o concreto reciclado CR indicaram que a zona de transição ZT é o elo mais fraco no concreto, interface entre a pasta de cimento e a AR (Nagataki et al., 2004). Portanto, a modificação da microestrutura na ZT tem sido uma das grandes preocupações para melhorar as propriedades do CR (Kong et al., 2010). Estudos de Nagataki et al. (2004) Kong et al. (2010) têm demonstrado que a ZT entre a AR e a nova matriz de cimento formam o elo fraco do concreto e afetam diretamente as suas 
propriedades mecânicas. Porém, um aperfeiçoamento tecnológico pode ser feito como melhoria no concreto através de um pré-tratamento do agregado reciclado AR com solução de sílica ativa, de $10 \%$ em peso (Katz, 2004). Segundo estudos sobre o processo de britagem, demonstra-se que este tratamento pode aumentar em torno de $15 \%$ a $30 \%$ a resistência à compressão nas idades de sete e 28 dias. No entanto, o processo de pré-tratamento, antes da produção de concreto, levará a um custo mais alto, limitando assim, sua aplicação na construção.

A composição do RCD, oriundo de cada uma das atividades que compõem os trabalhos da construção civil, é diferente, e também em cada etapa da obra, mas sempre há um produto que se sobressai, que é diferente em cada região, em razão da diversidade de tecnologias construtivas e de matérias-primas utilizadas na região (Ferreira, 2013). Sendo assim, o uso do RCD-R requer estudos continuados que possam contribuir para o avanço da Indústria da Construção Civil e da sustentabilidade no setor.

\section{O concreto produzido com RCD-R}

Segundo Leite (2001), Gomes e Brito (2009) e Cordeiro et al. (2017), o agregado reciclado apresenta características intrínsecas que afetam o desempenho dos concretos com ele produzidos. 0 formato irregular do agregado graúdo britado, a menor massa específica e a maior porosidade influenciam diretamente nas propriedades dos concretos, tanto no estado fresco, quanto no endurecido (Silva et al., 2020b).

Neste sentido, diversos autores como Leite (2001), Nagataki et al. (2004), Gomes, Brito (2009) e Cordeiro et al. (2017), vêm desenvolvendo estudos, principalmente em agregados reciclados de concreto, na tentativa de suprir e, ou, minimizar os efeitos negativos decorrentes das características desse material, utilizando para isso, tratamentos mecânicos, térmicos e químicos, que demandam, muitas vezes, custo e tempo, mas que levam a resultados satisfatórios.

Algumas pesquisas procuram otimizar as características dos agregados reciclados de concreto a partir da incorporação de finos reativos e não reativos, com o objetivo de envolver a superfície desse material com um cimento ou uma adição que preencha seus vazios e refine seus poros (Tam et al., 2005; Tam e Tam, 2008).

Nesta vertente da melhoria do desempenho do concreto com agregado reciclado, acredita-se que resultados satisfatórios possam ser atingidos relacionando-se, entre outros fatores, a sistematização de sua produção. Ao executar concretos com resíduos de construção, deve-se levar em conta suas peculiaridades, como a porosidade e a baixa resistência ao desgaste, visto que são materiais heterogêneos, que variam a cada lote coletado. Além disso, os concretos com resíduos apresentam peculiaridades em virtude de suas condições de mistura, concreto de origem e outros (Cordeiro et al., 2017).

0 concreto é uma estrutura composta de três fases em escala microscópica, compreendendo agregado graúdo, matriz de argamassa com agregado fino e zona de transição (ZT) entre o agregado graúdo e a matriz de argamassa (Poon et al., 2004). A ZT tem, tipicamente, 10-50 $\mu \mathrm{m}$ de espessura e influencia significativamente as propriedades do concreto. Conforme indicado na literatura por Tam et al. (2005); Tam e Tam (2008) a estrutura do concreto reciclado (CR) é muito mais complicada que a do concreto normal. 0 CR possui duas ZTs, uma entre o agregado e a nova pasta de cimento (nova ZT) e a outra entre o agregado e a argamassa antiga anexada (antiga ZT). A argamassa de cimento ligada e a ZT do agregado formam o elo fraco no CR, que é composto de muitos minúsculos poros e fissuras, e afetam criticamente a resistência final do CR. Esses poros e fissuras também absorvem a água, levando a um alto teor de água na nova ZT do CR. Assim, grandes cristais de hidróxido de cálcio $\mathrm{Ca}(\mathrm{OH})_{2}$ tendem a se formar no poro do agregado, e também tendem a se acumular na superfície da argamassa aderida "argamassa antiga" (Kong et al., 2010). 
Dentre os possíveis empregos do agregado reciclado, temos a fabricação de argamassa, contra pisos, meio-fio, granilite, blocos, tijolos de vedação e estrutural, pavimentação, pisos intertravados, manilhas de esgoto e outras alternativas (Bastos et al., 2016).

Uma das possíveis formas de utilização, é o aproveitamento dos resíduos de concreto na confecção de tijolos prensados de solo-cimento. O uso do solo-cimento na construção de habitações populares permite economia razoável, com redução de custos que podem atingir $40 \%$ da obra. Contribui para isso o baixo custo do solo, que é o material usado em maior quantidade, além de menores custos com transporte e energia, existindo ainda, a possibilidade de redução de custos com mão de obra, pois o processo não requer grande número profissionais especializados em construção. A ideia de misturar resíduos de construção na fabricação de tijolos de solo-cimento surgiu em função da possibilidade de melhorar suas características mecânicas, uma vez que as características físicas dos resíduos de argamassa e concreto se assemelham às dos pedregulhos (Mesquita et al., 2015).

Pesquisas realizadas sobre o uso de materiais cerâmicos, como adição ao concreto, estão sendo realizadas em vários países, como os estudos realizados por Aliabdo et al. (2014) no uso de RCD-R proveniente de material cerâmico (tijolo de barro) como agregado graúdo e miúdo para adição em concretos, substituindo 50\% e 100\% dos agregados para produção de blocos de vedação. As resistências à compressão dos blocos de alvenaria de concreto alcançaram resultados satisfatórios de 2,8 MPa e 5,2 MPa. Essas pesquisas relatam resultados satisfatórios, porém, requerem maiores cuidados e uma minuciosa análise desta interação entre concreto e material cerâmico.

\section{Produção de blocos com agregado reciclado}

Estudos desenvolvidos por Carneiro (2005) comprovam a viabilidade da utilização de agregados reciclados de RCD-R na produção de blocos para alvenaria sem função estrutural. Nos testes realizados, tanto os blocos produzidos com 30\% de substituição do agregado natural pelo agregado reciclado de RCD-R, quanto aqueles com $60 \%$ de substituição, apresentaram resistência à compressão simples superior ao estabelecido pela ABNT NBR 6136:2014 (ABNT, 2014).

Paula (2010) e Mesquita et al. (2015) estudaram a viabilidade da confecção de blocos com uso de agregados miúdos reciclados para uso em alvenaria de vedação, estabelecendo um traço padrão cimento/agregado miúdo de 1:6. Os resultados indicaram que a substituição de $25 \%, 50 \%, 75 \%$ e $100 \%$ da areia natural por agregados miúdos reciclados não afetou significativamente as propriedades mecânicas dos blocos cujos valores de resistência à compressão foram de 3,67 $\mathrm{MPa}, 2,63 \mathrm{MPa}, 2,44 \mathrm{MPa}$ e 2,03 $\mathrm{MPa}$, respectivamente.

De acordo com Buttler (2007) a resistência à compressão do bloco é o principal parâmetro de projeto da parede de alvenaria. Portanto, essa propriedade torna-se a principal variável de controle do processo produtivo do bloco. Além disso, para se garantir um bom desempenho dos blocos, alguns parâmetros devem ser analisados: matéria-prima, fator água/cimento, granulometria dos agregados, traço, tempo de mistura, vibração, prensagem, condições de cura, execução e manuseio do material (Bastos et al., 2016). 
Tabela 1. Requisitos para resistência característica à compressão, absorção e retração.

\begin{tabular}{|c|c|c|c|c|c|c|c|}
\hline \multirow[b]{3}{*}{ Classificação } & \multirow[b]{3}{*}{ Classe } & \multirow[b]{3}{*}{$\begin{array}{l}\text { Resistência } \\
\text { característica } \\
\text { compressão } \\
\text { axial (MPa) }\end{array}$} & \multicolumn{4}{|c|}{ Absorção \% } & \multirow[b]{3}{*}{ Retração \% } \\
\hline & & & \multicolumn{2}{|c|}{ Agregado Normal } & \multicolumn{2}{|c|}{ Agregado Leve } & \\
\hline & & & Individual & Média & Individual & Média & \\
\hline \multirow{2}{*}{ Função estrutural } & $\mathrm{A}$ & $\mathrm{fbk}>8,0$ & $<6,0$ & $<6,0$ & \multirow{3}{*}{$<16,0$} & \multirow{3}{*}{$<13,0$} & \multirow{3}{*}{$<0,065$} \\
\hline & $\mathrm{B}$ & $4,0<\mathrm{fbk}>8,0$ & $<10,0$ & $<8,0$ & & & \\
\hline $\begin{array}{l}\text { Sem função } \\
\text { estrutural }\end{array}$ & $\mathrm{C}$ & $\mathrm{fbk}>3,0$ & $<12,0$ & $<10,0$ & & & \\
\hline
\end{tabular}

Fonte: Adaptado da NBR 6132 (ABNT, 2014).

Um estudo comparativo foi realizado por Bastos, Cruz e Woelffel (2016) em blocos para vedação com resistência, conforme Norma NBR 6136 (ABNT, 2014), de aproximadamente 3,0 $\mathrm{MPa}$, confeccionados com agregados reciclados RCD-R e agregados convencionais. A Figura 3 apresenta os valores obtidos para o bloco convencional com o custo de $\mathrm{R} \$ 1,34$ e resistência de 2,0 $\mathrm{MPa}$, comparado ao bloco com agregado reciclado, cujo qual chegou a um custo de $\mathrm{R} \$ 0,65$ e resistência de 6,47 MPa.

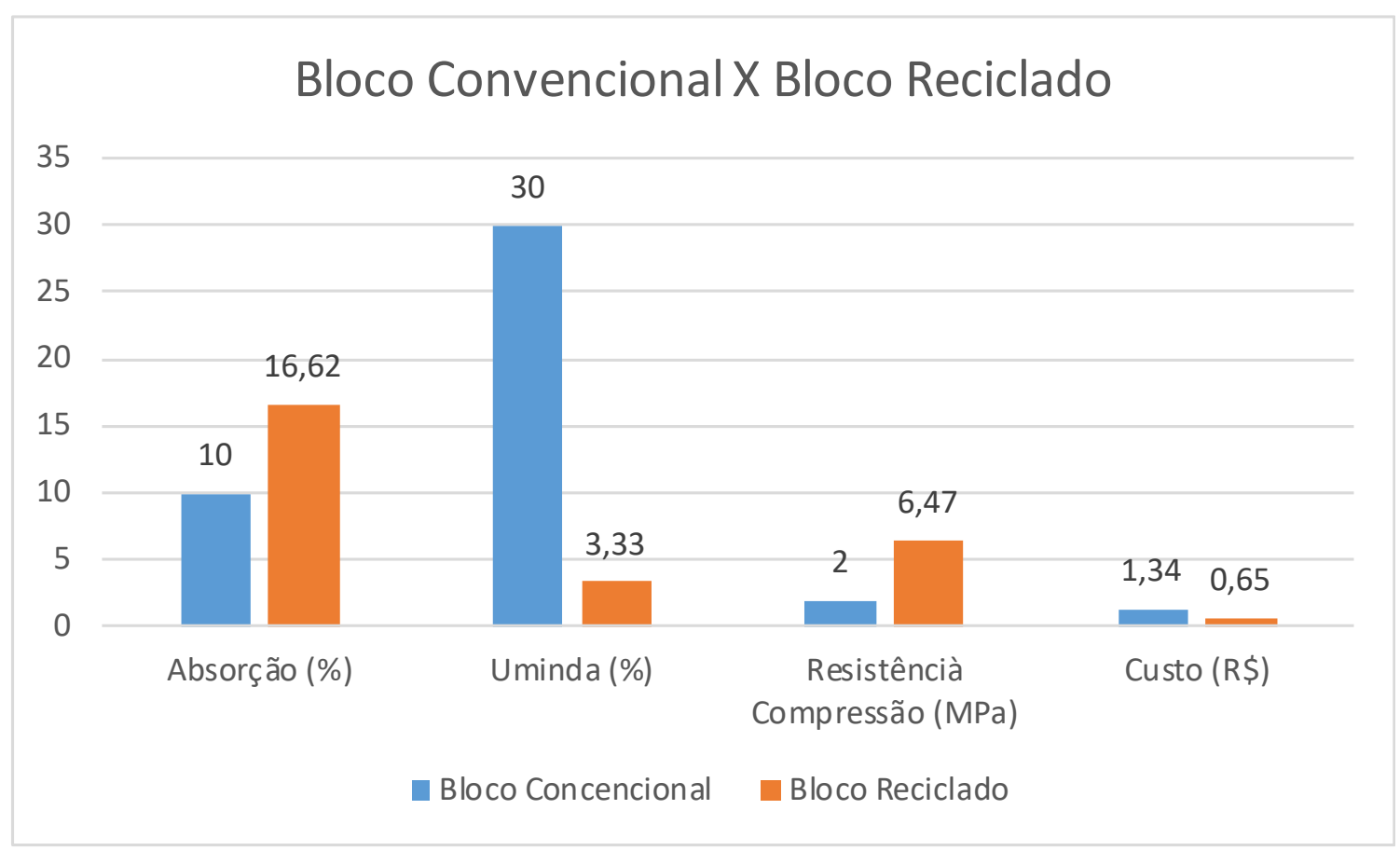

Figura 3. Comparativo dos blocos. Fonte: Adaptado de Bastos et al. (2016).

Os blocos de concreto produzidos com agregados reciclados de concretos de construção apresentam uma variabilidade quanto aos resultados da resistência à compressão. Entretanto, observaram que a melhor mistura é aquela em que o cimento é misturado com o agregado na condição saturada, superfície seca, seguido pela introdução 
e mistura da água de amassamento contendo aditivos incorporadores de ar (Lintz et al., 2012).

Para Lintz et al. (2012) concreto com porcentagens de até $60 \%$ de resíduos de construção parecem ser os mais indicados para a utilização na fabricação de blocos de concreto.

Em um estudo realizado com a substituição do agregado natural por agregado reciclado de RCD-R para produção de blocos estruturais de concreto, foram produzidos traços com substituição de $0 \%, 20 \%, 50 \%, 80 \%$ e $100 \%$ do agregado natural, ensaiados aos 14 e 28 dias de idade. Os blocos apresentaram resistências aceitáveis para a produção de blocos de concretos, tendo valores de resistência de 8,75 MPa, 7,18 MPa, 5,24 MPa, 4,93 MPa e 4,77 MPa. Os blocos foram submetidos aos ensaios para determinação da compressão e da capacidade de absorção de água. Os blocos com $20 \%$ e $50 \%$ apresentaram os melhores resultados com $94 \%$ e $58 \%$ do valor apresentado para o concreto de referência (Lintz et al., 2012).

\section{Conclusões}

O fator preponderante do uso deste material é o elo fraco entre agregado reciclado, argamassa velha (AD) e argamassa nova. Provocada pela alta porosidade das partículas recicladas e que podem ter essa argamassa porosa eliminada ou reduzida na fase de beneficiamento do RCD-R. Diversos estudos têm sido desenvolvidos com o objetivo de fortalecer o "elo fraco" do concreto reciclado, de modo a "reduzir a alta porosidade do agregado reciclado". Assim, fortalece-se tecnicamente o referencial teórico-científico, com base em estudos experimentais, para o uso deste material tão promissor com um custo baixo e com elevado ganho ambiental.

Britadores de eixo vertical e eixo inclinado, na britagem secundária e terciária, produzem partículas de forma mais quadrada ou arredondada e um aumento na produção de agregado miúdo e materiais pulverulentos. Isso ocorre devido ao processo mecânico do eixo rotor que provoca o atrito das partículas na superfície metálica do equipamento e o atrito com outras partículas, provocando o desgaste e lapidando o agregado. No caso do agregado reciclado de concreto, há uma maior retirada da argamassa velha "argamassa aderida" e nos agregados cerâmicos são extraídas as partes mais frágeis, permanecendo em sua maior parte, agregados resistentes.

O processo de beneficiamento do Resíduo de Construção e Demolição Reciclado tem forte influência nas propriedades mecânicas do agregado tais como: granulometria, forma, textura e densidade. As mesmas podem ser controladas favorecendo o uso do agregado em concretos sustentáveis e melhorando o desempenho do concreto reciclado aumentando-se, desta forma, o ganho ambiental.

\section{Conflito de interesses}

Os autores declaram não haver conflito de interesses.

\section{Referências}

ABCERAM - Associação Brasileira de Cerâmica. 2019. Disponível em: <https://abceram.org.br/definicao-e-classificacao/>. Acesso em: 20 maio 2019.

ABNT - Associação Brasileira de Normas Técnicas. NBR 6136: Blocos vazados de concreto simples para alvenaria - Requisitos. Rio de Janeiro: ABNT, 2014.

Afroughsabet, V.; Biolzi, L.; Ozbakkaloglu, T. Influence of double hooked-end steel fibers and slag on mechanical and durability properties of high performance recycled aggregate 
concrete. Composite Structures, v.181, p.273-284, 2017. https://doi.org/10.1016/ j.compstruct.2017.08.086

Aliabdo, A. A.; Abd-Elmoaty, A. E. M.; Hassan, H. H. Utilization of crushed clay brick in concrete industry. Alexandria Engineering Journal, v. 53, n. 1, p. 151-168, 2014. https://doi.org/10.1016/j.aej.2013.12.003

Alves, A. V.; Vieira, T. F.; Brito, J.; Correia, J. R. Mechanical properties of structural concrete with fine recycled ceramic aggregates. Construction and Building Materials, v. 64, p. 103-113, 2014. https://doi.org/10.1016/j.conbuildmat.2014.04.037

Amorim, P.; Brito, J. Concrete made with coarse concrete aggregate. ACI Materials Journal, v. 109, p. 195-204, 2012.

Bastos, I. A.; Cruz, L. F.; Woelffel, A. B. Fabricação de blocos de concreto para vedação com o uso de agregados reciclados em canteiro de obras. Revista Científica FAESA, v. 12, n. 1, p. 52-58, 2016. https://doi.org/10.5008/1809.7367.101

Brasil. Lei no 12.305, de 2 de agosto de 2010. Institui a Política Nacional de Resíduos Sólidos; altera a Lei no 9.605, de 12 de fevereiro de 1998; e dá outras providências. Disponível em: <http://www.planalto.gov.br/ccivil_03/_ato2007-2010/2010/lei/ l12305.htm>. Acesso em: 20 maio 2019.

Brasil. Resolução CONAMA no 307, de 5 de julho de 2002. Estabelece diretrizes, critérios e procedimentos para a gestão dos resíduos da construção civil. Disponível em: $<$ http://www2.mma.gov.br/port/conama/legiabre.cfm?codlegi=307>. Acesso em: 20 maio 2019.

Brasil. Resolução CONAMA no 348, de 16 de agosto de 2004. Altera a Resolução CONAMA no 307, de 5 de julho de 2002, incluindo o amianto na classe de resíduos perigosos. Disponível em: <http://www2.mma.gov.br/port/conama/legiabre.cfm? codlegi $=449>$. Acesso em: 20 maio 2019.

Brasileiro, L. L.; Matos, J. M. E. Revisão bibliográfica: reutilização de resíduos da construção e demolição na indústria da construção civil. Cerâmica, v. 61, n. 358, p. 178-189, 2015. https://doi.org/10.1590/0366-69132015613581860

Bravo, M.; Brito, J.; Pontes, J.; Evangelista, L. Durability performance of concrete with recycled aggregates from construction and demolition waste plants. Construction and Building Materials, v.77, p.357-369, 2015. https://doi.org/10.1016/j.conbuildmat. 2014.12.103

Buttler, A. M. Uso de agregado reciclado em concreto em blocos de alvenaria estrutural. São Carlos: Universidade de São Paulo, 2007. (Tese de doutorado).

Buttler, A. M.; Prado, D. M.; Corrêa, Márcio. R. S.; Márcio, A. R. Blocos estruturais de concreto com agregados reciclados de concreto: caracterização das propriedades físicas. Anais do ENTAC, p. 3540-3549, 2006.

Cabral, A.; Schalch, V.; Molin, D. D. Desempenho de concretos com agregados reciclados de cerâmica vermelha. Cerâmica, v. 55, p. 448-460, 2009.

Campos, R. S.; Barbosa, M. P.; Pimentel, L. L.; Maciel, G. F. Influência dos agregados reciclados nas propriedades reológicas e mecânicas do concreto autoadensável. Revista Materia, v. 23, n. 1, 2018. https://doi.org/10.1590/s1517-707620170001.0300

Carneiro, F. P. Diagnóstico e ações da atual situação dos resíduos de construção e demolição na Cidade do Recife. Recife: Universidade Federal de Pernambuco, 2005. (Dissertação de mestrado).

Rev. Bras. Gest. Amb. Sustent., 2020, vol. 7, n. 17, p. 1533-1541. 
Carvalho, M. T. M.; Caldas, L. R.; Sposto, R. M. Avaliação da sustentabilidade de habitações de interesse social a partir da especificação de materiais e elementos da edificação. Revista de Gestão Ambiental e Sustentabilidade, v. 9, n. 1, p. 1-25, 2020. https://doi.org/10.5585/geas.v8i2.904

Cordeiro, L. N. P.; Masuero, A. B.; Molin, D. C. C.; Souza, P. S. L.; Paes, I. N. L. Avaliação de processos de misturas de concretos com agregados graúdos reciclados. Ambiente

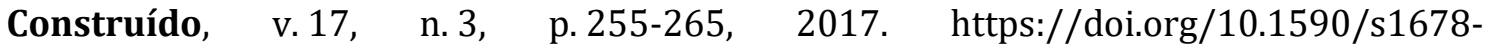
86212017000300174

Cortese, T. T.P.; Coutinho, S.V.; Penha, V. M.; Buckeridge, M.S. Tecnologias e sustentabilidade nas cidades. Estudos Avançados, v. 33, n. 97, p. 137-150, 2019. https://doi.org/10.1590/s0103-4014.2019.3397.008

El-Dieb, A. S.; Kanaan, D. M. Ceramic waste powder an alternative cement replacement: Characterization and evaluation. Sustainable Materials and Technologies, v. 17, e00063, 2018. https://doi.org/10.1016/j.susmat.2018.e00063

Etxeberria, M.; Vázquez, E.; Marí, A.; Barra, M. Influence of amount of recycled coarse aggregates and production process on properties of recycled aggregate concrete. Cement and Concrete Research, v. 37, n. 5, p. 735-742, 2007. https://doi.org/10.1016/ j.cemconres.2007.02.002

Ferreira, E. T. Contribuição ao estudo do potencial de aproveitamento de agregados reciclados de RCC produzidos na USIBEN - João Pessoa - em concreto estrutural aplicado em lajes pré-moldadas. Salvador: Universidade Federal da Bahia, 2013. (Tese de doutorado).

Frotté, C.; Nubila, C. S. A.; Nagalli, A.; Mazer, W.; Macioski, G.; Oliveira, L. O. S. Estudo das propriedades físicas e mecânicas de concreto com substituição parcial de agregado natural por agregado reciclado proveniente de RCD. Revista Materia, v. 22, n. 2, e11811, 2017. https://doi.org/10.1590/S1517-707620170002.0143

Gomes, M.; Brito, J. Structural concrete with incorporation of coarse recycled concrete and ceramic aggregates. Portugal Sb07 - Sustainable Construction, Materials and Practices: Challenge of the Industry for the New Millennium, Pts 1 and 2, p. 887-894, 2007.

Gomes, M.; Brito, J. Structural concrete with incorporation of coarse recycled concrete and ceramic aggregates: Durability performance. Materials and Structures, v. 42, n. 5, p. 663-675, 2009. https://doi.org/10.1617/s11527-008-9411-9

Gomes, P. C. C.; Ulsen, C.; Pereira, F. A.; Quattrone, M.; Angulo, S. C. Comminution and sizing processes of concrete block waste as recycled aggregates. Waste Management, v. 45, p. 171-179, 2015. https://doi.org/10.1016/j.wasman.2015.07.008

Guo, H.; Shi, C.; Guan, X.; Zhu, J.; Ding, Y.; Ling, T. C.; Zhang, H.; Wang, Y. Durability of recycled aggregate concrete: A review. Cement and Concrete Composites, v. 89, p. 251-259, 2018. https://doi.org/10.1016/j.cemconcomp.2018.03.008

Hansen, T. C. Recycled aggregates and recycled aggregate concrete second state-of-the-art report developments 1945-1985. Materials and Structures, v. 19, n. 3, p. 201-246, 1986. https://doi.org/10.1007/BF02472036

IPEA - Instituto de Pesquisa Econômica Aplicada. Diagnóstico dos resíduos sólidos da construção civil. Brasília: IPEA, 2012. (Relatório de pesquisa).

Karpinsk, A.; Pandolfo, R.; Reinehr, J.; Pandolfo, L.; Guimarães, J. Gestão diferenciada de resíduos da construção civil: uma abordagem ambiental. Porto Alegre: EDIPUCRS, 2009. 
Katkhuda, H.; Shatarat, N. Improving the mechanical properties of recycled concrete aggregate using chopped basalt fibers and acid treatment. Construction and Building Materials, v. 140, p. 328-335, 2017. https://doi.org/10.1016/j.conbuildmat.2017.02.128

Katz, A. Treatments for the improvement of recycled aggregate. Journal of Materials in Civil Engineering, v. 16, n. 6, p. 597-603, 2004. https://doi.org/10.1061/(ASCE)08991561(2004)16:6(597)

Kim, Y.; Hanif, A.; Kazmi, S. M. S.; Munir, M. J.; Park, C. Properties enhancement of recycled aggregate concrete through pretreatment of coarse aggregates: Comparative assessment of assorted techniques. Journal of Cleaner Production, v. 191, p. 339-349, 2018. https://doi.org/10.1016/j.jclepro.2018.04.192

Kisku, N.; Joshi, H.; Ansari, M.; Panda, S. K.; Nayak, S.; Dutta, S. C. A critical review and assessment for usage of recycled aggregate as sustainable construction material. Construction and Building Materials, v. 131, p. 721-740, 2017. https://doi.org/ 10.1016/j.conbuildmat.2016.11.029

Kong, D.; Lei, T.; Zheng, J.; Ma, C.; Jiang, J.; Jiang, J. Effect and mechanism of surface-coating pozzalanics materials around aggregate on properties and ITZ microstructure of recycled aggregate concrete. Construction and Building Materials, v. 24, n. 5, p. 701-708, 2010. https://doi.org/10.1016/j.conbuildmat.2009.10.038

Le, T.; Le, S. G.; Garcia-Diaz, E.; Betrancourt, D.; Rémond, S. Hardened behavior of mortar based on recycled aggregate: Influence of saturation state at macro- and microscopic scales. Construction and Building Materials, v. 141, p. 479-490, 2017. https://doi.org/ 10.1016/j.conbuildmat.2017.02.035

Leite, M. B. Avaliação de propriedades mecânicas de concreto produzidos com agregados reciclados de resíduos de construção. Porto Alegre: Universidade Federal do Rio Grande do Sul, 2001.

Leite, M. B.; Monteiro, P. J. M. Microstructural analysis of recycled concrete using X-ray microtomography. Cement and Concrete Research, v. 81, p. 38-48, 2016. https://doi.org/10.1016/j.cemconres.2015.11.010

Lintz, R. C. C.; Jacintho, A. E. P. G. A.; Pimentel, L. L.; Gachet-Barbosa, L. A. Study of the reuse of construction residues in concrete employed by blocks manufacture. Revista IBRACON de Estruturas e Materiais, v. 5, n. 2, p. 166-181, 2012. https://doi.org/10.1590/s198341952012000200004

Malešev, M.; Radonjanin, V.; Marinković, S. Recycled concrete as aggregate for structural concrete production. Sustainability, v. 2, n. 5, p.1204-1225, 2010. https://doi.org/ $10.3390 /$ su2051204

Martins, D. J.; Correia, J. R.; Brito, J. The effect of high temperature on the residual mechanical performance of concrete made with recycled ceramic coarse aggregates. Fire and Materials, v. 40, n. 2, p. 289-304, 2016. https://doi.org/10.1002/fam.2287

Mesquita, L, C.; D’Almeida D. A. I. C.; Cândido, E. S.; Cathoud, G. A. Análise da viabilidade técnica de utilização de resíduos de construção e demolição na fabricação de blocos de vedação. REEC - Revista Eletrônica de Engenharia Civil, v. 10, n. 3, p. 30-40, 2015. https://doi.org/10.5216/reec.V10i3.32651

Nagataki, S.; Gokce, A.; Saeki, T.; Hisada, M. Assessment of recycling process induced damage sensitivity of recycled concrete aggregates. Cement and Concrete Research, v. 34, n. 6, p. 965-971, 2004. https://doi.org/10.1016/j.cemconres.2003.11.008 
Paula, P. R. Utilização dos resíduos da construção civil na produção de blocos de argamassa sem função estrutural. Recife: Universidade Católica de Pernambuco, 2010.

Poon, C. S.; Shui, Z. H.; Lam, L. Effect of microstructure of ITZ on compressive strength of concrete prepared with recycled aggregates. Construction and Building Materials, v. 18, n. 6, p. 461-468, 2004. https://doi.org/10.1016/j.conbuildmat.2004.03.005

Ribeiro, F. A. B. S.; Dias, J. F. Análise da atividade de transporte, triagem e transbordo de RCD em Uberlândia/MG. Revista Nacional de Gerenciamento de Cidades, v. 1, n. 5, p. 69-87, 2013. https://doi.org/10.17271/23188472152013514

Saeedi Javadi, A.; Badiee, H.; Sabermahani, M. Mechanical properties and durability of bio-blocks with recycled concrete aggregates. Construction and Building Materials, v. 165, p. 859-865, 2018. https://doi.org/10.1016/j.conbuildmat.2018.01.079

Santana, V. M.; Paes, F. P.; Santana, D. S.; Cerqueira, M. B. S.; Silva, F. G. S.; Aragão, H. G. Utilização de concreto reciclado na aplicação de elementos estruturais. Anais do XV Encontro Latino Americano de Iniciação Científica e do XI Encontro Latino Americano de Pós-Graduação, p. 1-6, 2011.

Senthamarai, R. M.; Devadas Manoharan, P. Concrete with ceramic waste aggregate. Cement and Concrete Composites, v. 27, n. 9/10, p. 910-913, 2005. https://doi.org/ 10.1016/j.cemconcomp.2005.04.003

Shaban, W. M.; Yang, J.; Su, H.; Mo, K. H.; Li, L.; Xie, J. Quality improvement techniques for recycled concrete aggregate: A review. Journal of Advanced Concrete Technology, v. 17, n. 4, p. 151-167, 2019a. https://doi.org/10.3151/jact.17.4.151

Shaban, W. M.; Yang, J.; Su, H.; Liu, Q.; Tsang, D. C. W.; Wang.; Xie, J.; Li, L. Properties of recycled concrete aggregates strengthened by different types of pozzolan slurry. Construction and Building Materials, v. 216, p.632-647, 2019b. https://doi.org/ 10.1016/j.conbuildmat.2019.04.231

Silva, D. A. E. Estudo da influência do índice de forma do graúdo nas propriedades mecânicas do concreto. Goiânia: Universidade Federal de Goiás, 2012. (Dissertação de mestrado).

Silva, D. A. E.; Melo, C. E. L. Processo de britagem e sua influência nas características físicas do agregado graúdo para concreto. Paranoá: Cadernos de Arquitetura e Urbanismo, v. 26, n. 3, p. 36-47, 2020. https://doi.org/10.18830/issn.1679-0944.n26.2020.03

Silva, D. A.; Geyer, L. B. Análise e classificação da forma do agregado graúdo britado para concreto. Revista Científica Multidisciplinar Núcleo do Conhecimento, v. 5, n. 12, p. 18-28, 2018a.

Silva, D. A.; Geyer, L. B. Influência da forma do agregado graúdo nas propriedades mecânicas do concreto. Revista Científica Multidisciplinar Núcleo do Conhecimento, v. 5, n. 12, p. 67-82, 2018b.

Silva, D. A.; Geyer, L. B.; Pantoja, J. C. Estudo da forma do agregado graúdo e sua influência no módulo de elastricidade do concreto. Brazilian Journal of Development, v. 6, n. 8, p. 60426-60440, 2020a. https://doi.org/10.34117/bjdv6n8-453

Silva, D. A.; Geyer, L. B.; Pantoja, J. C. Porosidade do concreto versus forma do agregado graúdo. Brazilian Journal of Development, v. 6, n. 8, p. 60359-60376, 2020b. https://doi.org/10.34117/bjdv6n8-449 
Silva, O. H.; Umada, M. K.; Polastri, P.; Angelis Neto, G.; Angelis, B. L. D.; Miotto, J. L. Etapas do gerenciamento de resíduos da construção civil. Revista Eletrônica em Gestão, Educação e Tecnologia Ambiental, v. 19, p. 39-48, 2015.

Silva, R. V.; Brito, J.; Dhir, R. K. Properties and composition of recycled aggregates from construction and demolition waste suitable for concrete production. Construction and $\begin{array}{lllll}\text { Building Materials, } & \text { v. } 65, & \text { p. 201-217, 2014. https://doi.org/10.1016/ }\end{array}$ j.conbuildmat.2014.04.117

Silva, R. W.; Arnosti, J. S. Caracterização do resíduo de construção e demolição (RCD). Holos Environment, $\quad$ v. 5, n. 2, p.137-151, 2005. https://doi.org/10.14295/ holos.v5i2.319

Stroher, A, P.; Kato, D. S.; Yamaguchi, N. U.; Couto, O. M. Utilização da cerâmica de entulho na substituição de agregado graúdo do concreto. Cerâmica Industrial, v. 22, n. 4, p. 34-46, 2017. https://doi.org/10.4322/cerind.2017.001

Tam, V. W. Y.; Gao, X. F.; Tam, C. M. Microstructural analysis of recycled aggregate concrete produced from two-stage mixing approach. Cement and Concrete Research, v. 35, n. 6, p. 1195-1203, 2005. https://doi.org/10.1016/j.cemconres.2004.10.025

Tam, V. W. Y.; Tam, C. M. Diversifying two-stage mixing approach (TSMA) for recycled aggregate concrete: TSMAs and TSMAsc. Construction and Building Materials, v. 22, n. 10, p. 2068-2077, 2008. https://doi.org/10.1016/j.conbuildmat.2007.07.024

Tenório, J. J. L.; Gomes, P. C. C.; Rodrigues, C. C.; Alencar, T. F. F. Concrete produced with recycled aggregates. Revista IBRACON de Estruturas e Materiais, v. 5, n. 5, p. 692-701, 2012. https://doi.org/10.1590/s1983-41952012000500006

Thomas, J.; Thaickavil, N. N.; Wilson, P. M. Strength and durability of concrete containing recycled concrete aggregates. Journal of Building Engineering, v. 19, p. 349-365, 2018. https://doi.org/10.1016/j.jobe.2018.05.007

Ulsen, C.; Kahn, H.; Hawlitschek, G.; Masini, E. A.; Angulo, S. C.; John, V. M. Production of recycled sand from construction and demolition waste. Construction and Building Materials, v. 40, p. 1168-1173, 2013. https://doi.org/10.1016/j.conbuildmat.2012.02.004

Verian, K. P.; Ashraf, W.; Cao, Y. Properties of recycled concrete aggregate and their influence in new concrete production. Resources, Conservation and Recycling, v. 133, p. 30-49, 2018. https://doi.org/10.1016/j.resconrec.2018.02.005

Vieira, T.; Alves, A.; Brito, J.; Correia, J. R.; Silva, R. V. Durability-related performance of concrete containing fine recycled aggregates from crushed bricks and sanitary ware. Materials and Design, v. 90, p.767-776, 2016. https://doi.org/10.1016/ j.matdes.2015.11.023

Wong, C. L.; Mo, K. H.; Yap, S. P.; Alengaram, U. J.; Ling, T. Potential use of brick waste as alternate concrete-making materials: A review. Journal of Cleaner Production, v. 195, p. 226-239, 2018. https://doi.org/10.1016/j.jclepro.2018.05.193

Xiao, J.; Li, W.; Fan, Y.; Huang, X. An overview of study on recycled aggregate concrete in China (1996-2011). Construction and Building Materials, v. 31, p. 364-383, 2012. https://doi.org/10.1016/j.conbuildmat.2011.12.074 